\title{
Capacitor Discharge Spot Welding of Aluminum, Part 1: Weldability Assessments
}

\section{The Weldability response for polarity-switching CD-based resistance spot welding is compared with that done using MFDC power}

\author{
BY J. E. GOULD, L. LINDAMOOD, J. MALPICA, P. LESTER, AND D. ZHU
}

\begin{abstract}
A key aspect of integrating automotive sheet into automotive production are the costs associated with joining. While the majority of sheet steel assembly is done with resistance spot welding, that has not readily translated to aluminum. Resistance spot welding of aluminum sheet is challenged by high current demand as well as reduced electrode life. In the latter case, direct current (DC) power supplied by state-of-the-art systems has exacerbated the problem. Recently, technology employing capacitor discharge (CD) welding in conjunction with polarity switching has been developed. This work is a first effort in examining the response of resistance spot welding on aluminum sheet to polarity-switching CD power. In this paper, the current range response between medium-frequency DC (MFDC) and polarity-switching $C D$ was investigated. It was found that polarity-switching CD welding offered improved current ranges over MFDC. In addition, replicate mechanical testing cross-tension results were similar, but tensile shear strengths improved nominally $20-25 \%$. Finally, some limited tests were done to assess the suitability of CD resistance spot welding in the presence of an adhesive. Current range tests with and without a prepulse were done, and both showed excellent weldability.
\end{abstract}

\section{KEYWORDS}

- Capacitor Discharge Welding - Aluminum Sheet

- Resistance Spot Welding • Current Range Testing

- Spot Weld Mechanical Performance

\section{Introduction}

Aluminum sheet for high-volume body-in-white construction has been investigated for many decades (Ref. 1). A key aspect for implementation is the ability to join sheet metal components to one another, thus achieving structural components. The primary method of creating such sheet metal joints in the automotive industry is through resistance spot welding (Refs. 2-5). Considerable research has been conducted over the years to adapt resistance spot welding to aluminum sheet (Refs. 1, 3-5). One major challenge in the application of resistance spot welding for aluminum sheet has been that of electrode life.

Many initial evaluations assessing spot weldability of aluminum sheet were done with alternating current $(\mathrm{AC})$ power supplies (Refs. 1, 3-5). Life performance in such systems is dominated by the design of the electrode, the condition of the aluminum sheet surfaces, and the welding time itself (Refs. 6-9). Challenges in electrode life changed dramatically with the introduction of medium-frequency direct current (MFDC) power supplies. Three-phase MFDC power supplies include primary rectification, switching at frequencies in the hundreds to thousands of hertz range, and transformer voltage reduction. The output of the transformers is then rectified to provide DC current in the welding secondary (Ref. 10). The approach allows for significantly reduced mass in the transformer, as well as an improved power factor compared to AC for resistance spot welding. Both improve the economics of spot welding in production (Ref. 10).

MFDC power supplies are now the dominant technology for resistance welding in the automotive industry (Ref. 2). However, with respect to aluminum alloys, the use of DC power supplies resulted in an order-of-magnitude drop in electrode life (Refs. 1, 12,13). This reduction in life was associated with Peltier voltages occurring at the electrodesheet contact surfaces (Ref. 12). The Peltier voltages near the melting point of aluminum are a significant fraction of that occurring across the tips during welding. The effect moves a significant amount of the heat from one electrodesheet surface to the other, causing accelerated electrode wear at that location.

Recently, use of polarity switching at the output of an MFDC transformer has been commercialized as a possible 


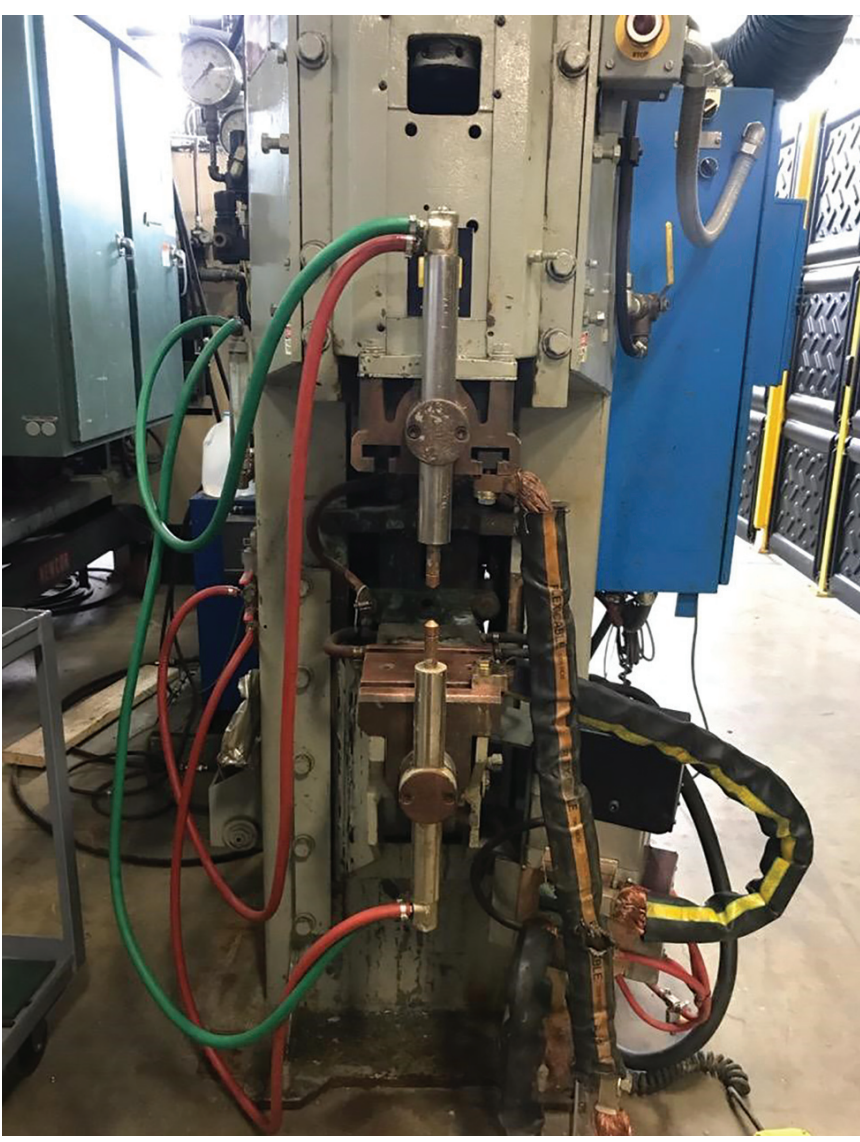

Fig. 1 - MFDC system integrated into a pedestal-type frame.

Table 1 - Coupon Sizes for the Various Tests Conducted as Part of This Study

Test Configuration Width $(\mathrm{mm}) \quad$ Length $(\mathrm{mm})$

\begin{tabular}{ccc}
\hline Peel testing & 25 & 100 \\
Tensile shear testing & 25 & 100 \\
Cross-tension testing & 50 & 150 \\
\hline
\end{tabular}

solution to this problem (Ref. 14). Polarity switching of the MFDC power allows the direction of the Peltier voltages to change from weld to weld. This has the advantage of balancing erosion across the two electrodes, thus potentially extending the resulting life. However, the switching network used has limited allowable current capability and has not been suitable for a wide range of aluminum sheet materials.

An alternative to polarity-switching MFDC is comparable technology done in conjunction with capacitor discharge (CD) power supplies. This patented methodology (Ref. 15) has been implemented into a resistance spot welding system (Ref. 16). With this technology, a switching network is used at the output of the capacitors, delivering opposite polarities to successive welds. The existing system $(\sim 3 \mathrm{~kJ})$ has shown deliverable currents in excess of $90 \mathrm{kA}$. In addition, polarity switching facilitates the use of conventional (AC)

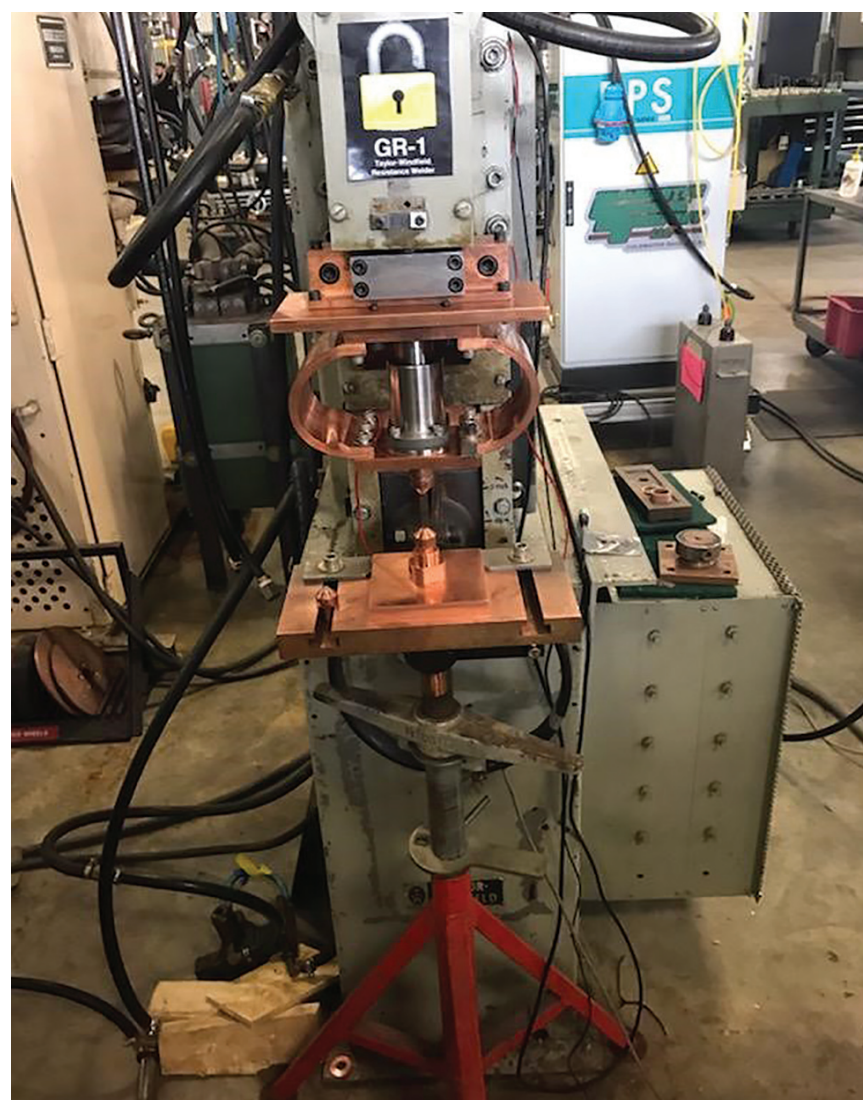

Fig. 2 - Polarity-switching $C D$ system integrated into a pedestal-type frame.

welding transformers, allowing simple changes in windings ratios. Changing the windings ratios affects the current pulse width in the welding secondary. The system has delivered pulse widths as short as $5 \mathrm{~ms}$ and as long as $30 \mathrm{~ms}$.

The work described here is intended to assess the relative welding performance (compared to conventional MFDC methods) using the existing polarity-switching $C D$ system. The results from this effort suggest benefits in manufacturing robustness, metallurgical integrity, and particularly electrode life. This work is covered in two parts. This first paper addresses basic weldability as assessed through current range testing, as well as the resulting mechanical properties, metallurgical weld quality, and compatibility with adhesives. A follow-on paper (Ref. 17) will address relative electrode wear performance. In that paper, improvements in both the electrode life and the potential for welding system changes (i.e., elimination of cooling water) are addressed.

\section{Experimental Procedures}

All work was done using 1-mm-thick 5182 aluminum sheet. The material has a composition of nominally $4-5 \%$ $\mathrm{Mg}$ and $0.2-0.5 \% \mathrm{Mn}$ (Ref. 18). This is a work hardened alloy with good corrosion resistance and is generally intended for nonexposed applications. All materials were cut into coupons for the respective tests. Coupon dimensions and the test configuration are provided in Table 1. Coupon sizes for peel, tensile shear, cross-tension, and electrode life test- 


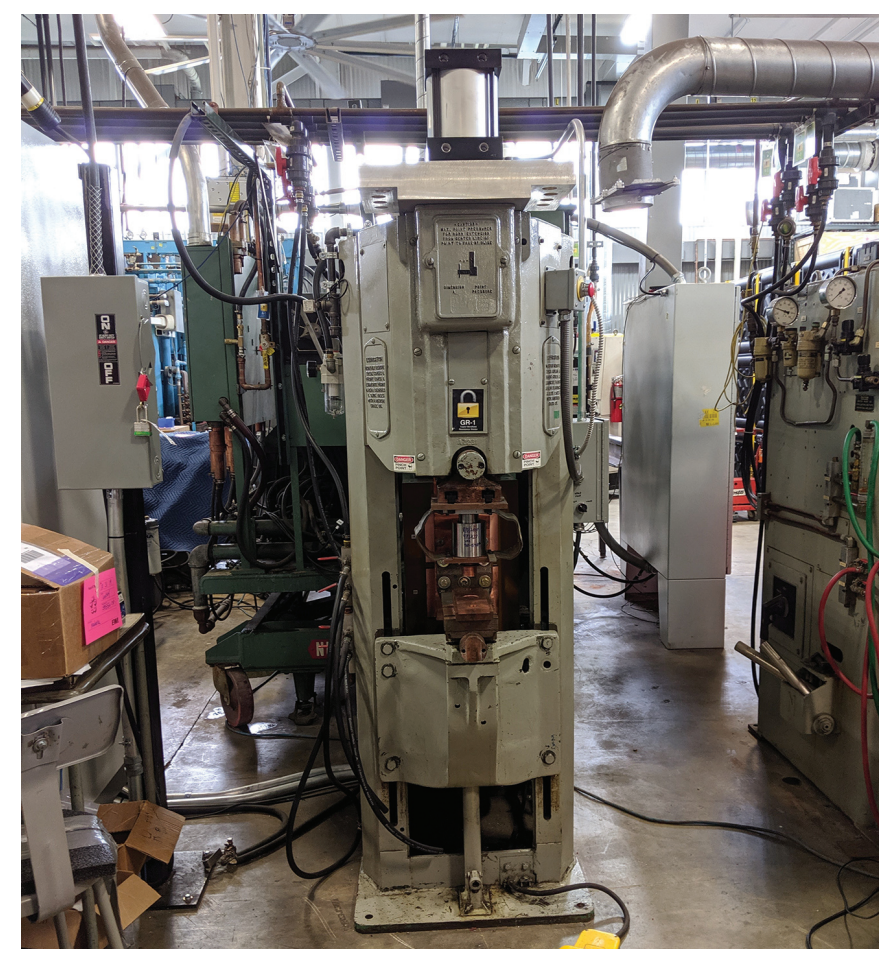

Fig. $3-20-k J$ Kapkon CD welding power supply integrated into a press frame.

ing were taken from the appropriate American Welding Society (AWS) Standards (Refs. 19, 20). For the weld bonding efforts, a DOW BETAMATE ${ }^{\mathrm{TM}} 1630$ adhesive was employed.

For this work, three configurations of resistance welding power supplies were used. The baseline MFDC studies were done with a 500-A Miyachi inverter coupled with a 150-kVA transformer and a pedestal frame. This pedestal frame can provide welding loads up to roughly $12 \mathrm{kN}$. The system is shown in Fig. 1. Baseline CD studies were done with the EWI designed and assembled polarity-switching system described previously. That system includes a $1280-\mu \mathrm{F}$ capacitor and can be charged to a peak voltage of $2100 \mathrm{~V}$. This yields a peak energy capability of roughly $3 \mathrm{~kJ}$. The power supply includes a polarity-switching network and is programmed to reverse the direction of current flow on successive welds. As mentioned above, polarity switching prevents saturation of the transformer with consecutive welds. This power supply was then integrated with a small welding frame and 30-kVA transformer setup. A 75:1 transformer turns ratio was used to create the secondary voltages necessary for welding. The pedestal system with $C D$ power is shown in Fig. 2. The frame offers welding forces up to roughly 4.5 kN. Finally, a Kapkon $20-k J$ system was employed for the welding with adhesive studies. This power supply is a unique configuration with four capacitors that can be fired either simultaneously or in succession. This provides the possibility of integrating a preheat pulse into the welding cycle. The power supply was coupled through a special gap core transformer intended for CD welding into a pedestal frame. The frame is capable of welding loads up to $12 \mathrm{kN}$. The system as configured is shown in Fig. 3. In Figs. 2 and 3 , it can be seen that the two CD system configurations employed local spring-based, fast follow-up heads. These were

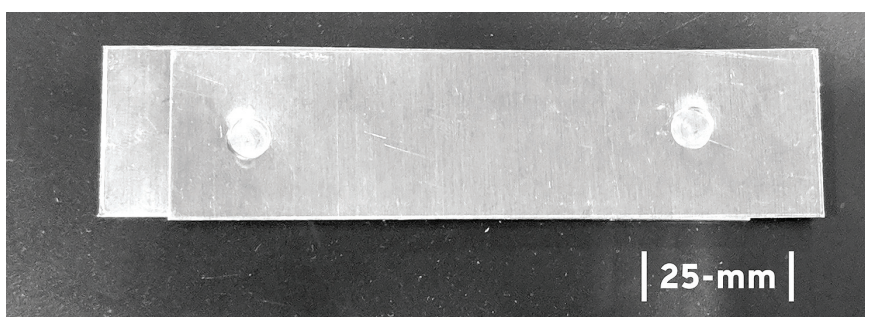

Fig. 4-A welded peel test coupon. Peel testing is done on the second weld made.

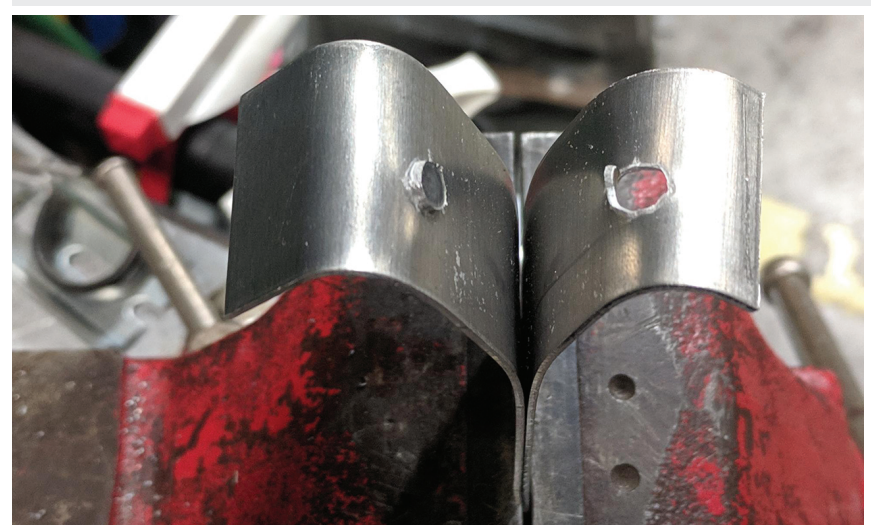

Fig. 5 - Results from a peel tested weld. Note the retained button on one side of the peeled coupon.

necessary to prevent, metal expulsion associated with the relatively narrow current pulse widths of $C D$ welding.

All welding systems were also subjected to monitoring of the welding current. For the polarity-switching CD and MFDC systems, this was done through a Miyachi 326-A weld checker coupled to a Yokogawa recording oscilloscope. For the Kapkon CD welding unit, data was taken directly from the internal monitoring capability.

Current range testing was done nominally according to AWS Standards (Ref. 20). This included placing two welds on overlapped nominally $25-\times 100-\mathrm{mm}$ coupons and then peeling the second weld. The as-welded coupon is shown in Fig. 4, while a sample peel test is shown in Fig. 5. For current range testing, the current was progressively increased from no-weld to excessive expulsion, and the resulting button size measured from the second weld of the peel test coupon. For each peeled button, maximum and minimum diameters were recorded, and the average value was used as the measure of performance. It is of note that the two power supplies employed different power control schemes. For the MFDC trials, the developed range were done in the constant-current mode. In this case, the desired current was programmed into the controller and maintained using a feedback loop. For the CD trials, the charge voltage was programmed onto the caps, and the resultant current discharge was monitored and recorded.

Additional procedures were used for the trials employing the adhesive. Here, the adhesive was applied to the samples as a nominal 3-mm-diameter bead, extending across the width of the coupon in the area for welding. The adhesive then was spread over the coupon area by the compressive action of the welding electrodes.

Mechanical testing was done for representative welded 


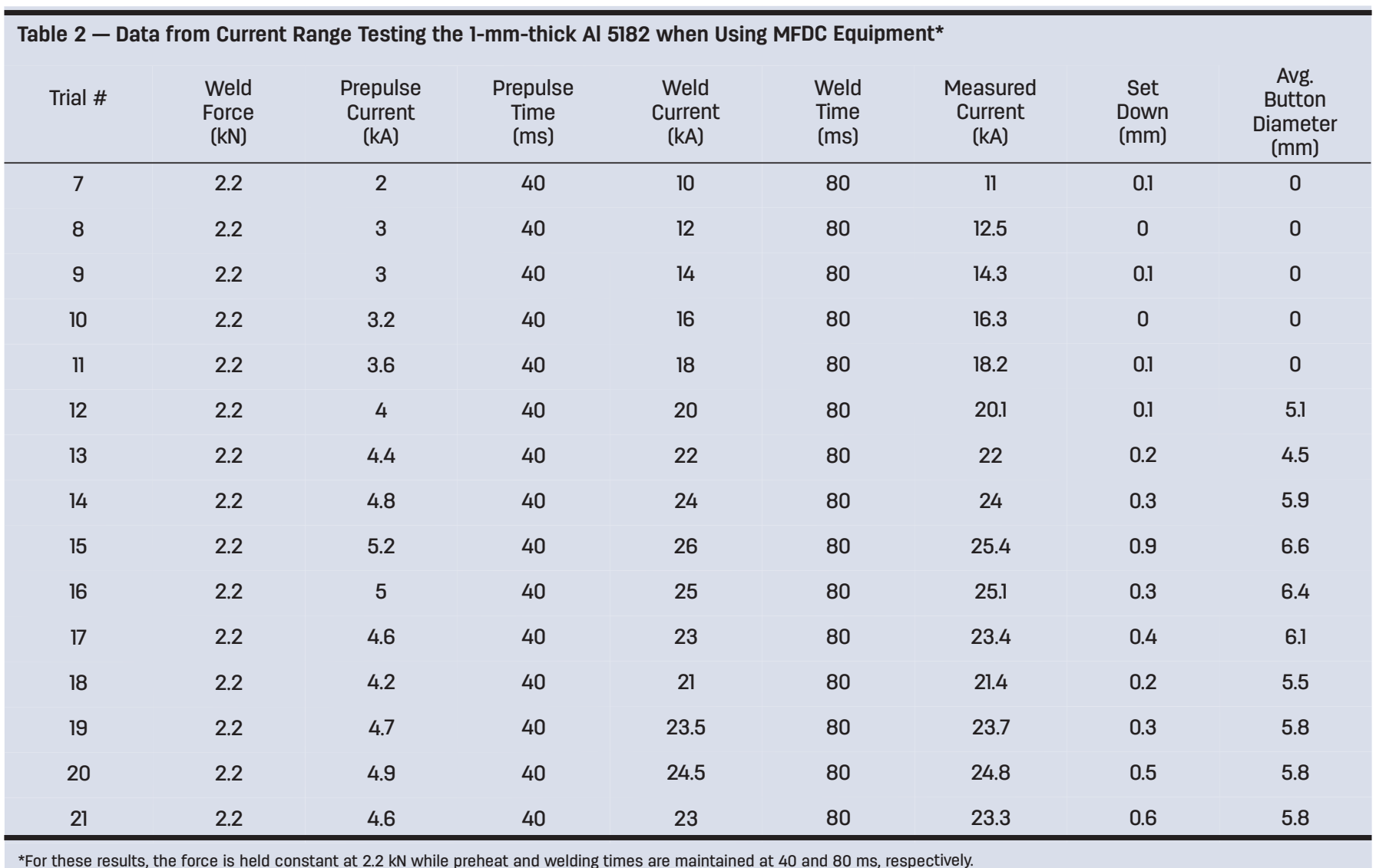

*For these results, the force is held constant at $2.2 \mathrm{kN}$ while preheat and welding times are maintained at 40 and 80 ms, respectively.

specimens in both the tensile shear and cross-tension orientations. Geometries of the test coupons are provided in Figs. 6 and 7. These geometries are taken directly from the AWS Standards (Ref. 19). Tensile shear testing is done with a single joint between the $25-\times 100-\mathrm{mm}$ coupons and is intended to provide mechanical properties data when the primary loading direction is perpendicular to the through thickness of the sheet. Cross-tension testing is done between the $50-x$ $150-\mathrm{mm}$ coupons and is intended to provide data when there are peel loads along the complete circumference of the weld.

Finally, samples for metallographic examination were prepared. This included epoxy cold mounting and polishing using standard techniques. Samples were etched in a solution of $2 \% \mathrm{HF}, 5 \% \mathrm{H}_{2} \mathrm{O}_{2}$, bal. water solution. This etchant provides good resolution of both the heat-affected zone (HAZ) and nugget sizes. Metallography was done using an Olympus BX51 system. In addition, representative samples were also subject to automated hardness testing. Testing was done using a LECO LM247AT automated system with a diamond pyramid indenter and a nominal 2-N (200-gf) contact force. Testing was done with a $400-\mu \mathrm{m}$ spacing in the through-thickness direction and a $300-\mu \mathrm{m}$ step distance across the weld. This testing conformed to American Society for Testing and Materials guidelines for microhardness testing (Ref. 21).

\section{Results}

The current range curve conducted using the MFDC power supply was done using truncated cone electrodes with a nominal 5-mm face diameter, a 2.2-kN welding force, and an 80 -ms heating time. In addition, a 40 -ms prepulse at $20 \%$ the main welding current was employed. Previous experience has shown that this prepulse helps mitigate bond line failures during peel testing (Refs. 1, 9, 10). A sample current waveform is shown in Fig. 8. The prepulse current $(\sim 5 \mathrm{kA})$ is clearly evident compared to the main pulse $(\sim 24 \mathrm{kA})$. The total current duration is roughly $120 \mathrm{~ms}$. Process data for the current range trials are provided in Table 2 . As seen in this table, measured welding currents ranged from 11 to $25.5 \mathrm{kA}$. As suggested above, prepulse currents were maintained at about $20 \%$ of that seen for the main welding pulse. The key response measures were set-down or total indentation of the electrodes as well as the diameter of the resulting button. Here, the majority of the indentations ranged from 0 to about $0.5 \mathrm{~mm}$. Of note, there was one weld with excessively large indentation, and this occurred at expulsion. Weld button sizes ranged from 0 up to about $6.5 \mathrm{~mm}$ (welds predominantly pulled buttons, as indicated in Fig. 5). The resulting current range for MFDC welding is shown in Fig. 9. For the 1-mm-thick material, the minimum sized weld standard was roughly $4 \mathrm{~mm}$ (Ref. 18). Figure 9 suggests that the current range from this minimum sized weld up to expulsion was about $5 \mathrm{kA}$. Indentations at minimum sized welds were only about $0.1 \mathrm{~mm}$. However, the observed indentation increased sharply as the button size increased.

A representative weld nugget from the top end of the current range was sectioned and examined metallographically. That joint was made at current levels 4.6 and $23 \mathrm{kA}$ for the preheat and main weld pulses, respectively. This represents a condition roughly $2 \mathrm{kA}$ below the expulsion level. Details 


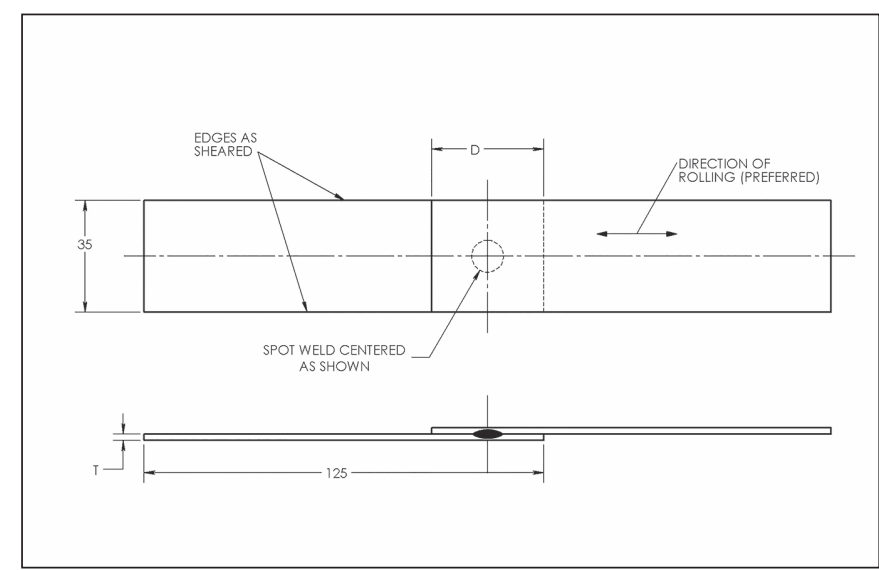

Fig. 6-Details of the tensile shear specimen design. The design is taken directly from Ref. 19.

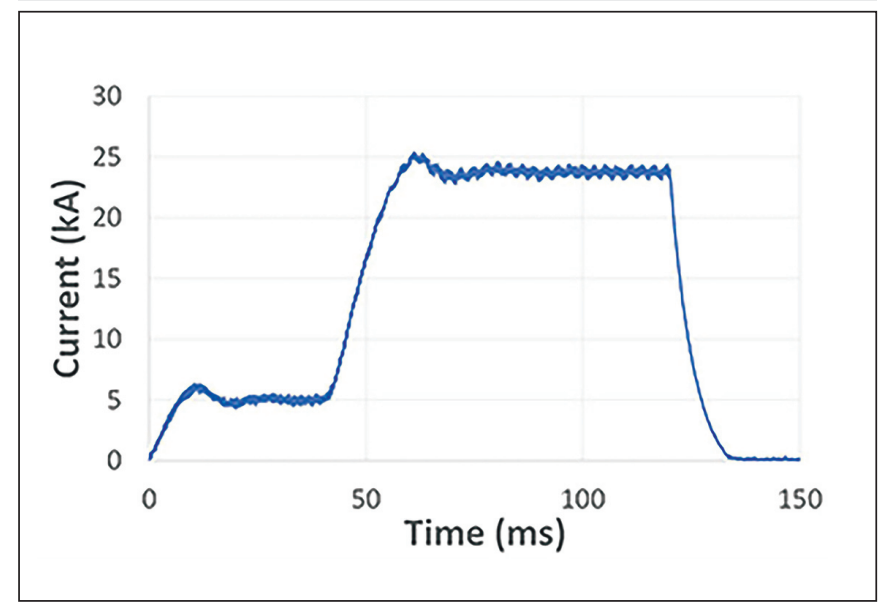

Fig. 8 - Current waveform for the welds made with the MFDC power supply. Waveform was taken just below expulsion.

of that weld are provided in Fig. 10.

Figure $10 \mathrm{~A}$ shows a macroview of the weld cross section, where the nugget penetration is $60-80 \%$ of the remaining metal thickness. In addition, there is significant weld porosity and cracking. Furthermore, electrode wear is evident by the indentations at, particularly the upper surface of the weld. In Fig. 10A, the HAZ and area of weld porosity are noted with the yellow letters " $A$ " and "B," respectively. These areas are shown at higher magnification in Fig. 10B and $C$. Figure 10B provides some detail of the HAZ. It is of note that there are indications of liquation cracks running in the HAZ adjacent to the fusion zone. The center of the weld (Fig. 10C) shows an equiaxed solidification structure and considerable grain boundary liquation. On this micrograph, an area of this equiaxed structure is indicated by the yellow label "C." This area is shown at even higher magnification in Fig. 10D. Here, the structure appears cellular/dendritic, with an apparent dendrite arm spacing on the order of $5 \mu \mathrm{m}$. There also appears to be significant segregation in this region of the weld.

This weld was also subjected to hardness mapping. Results of this hardness map are provided in Fig. 11. The map first indicates some localized hardening in and around the metallurgically observable HAZ. This is probably related to

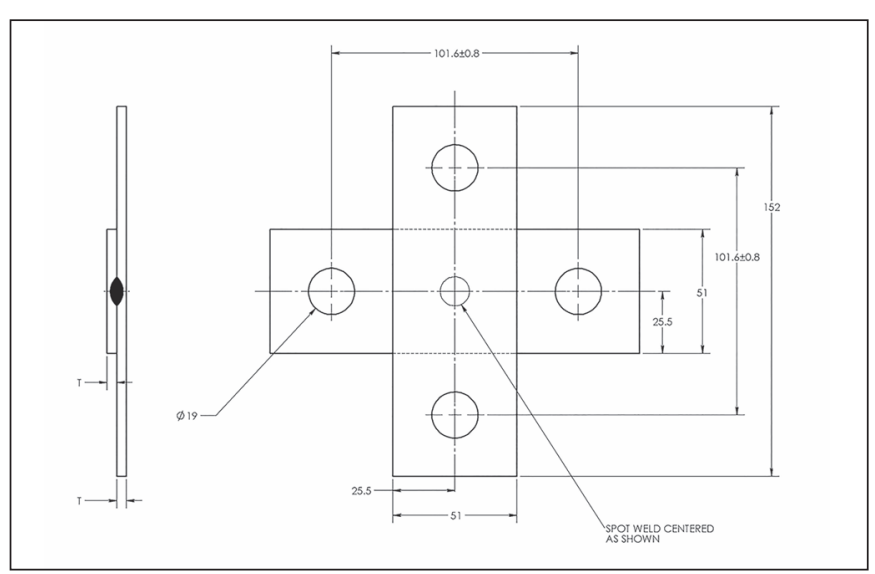

Fig. 7-Details of the cross-tension specimen design. The design is taken directly from Ref. 19.

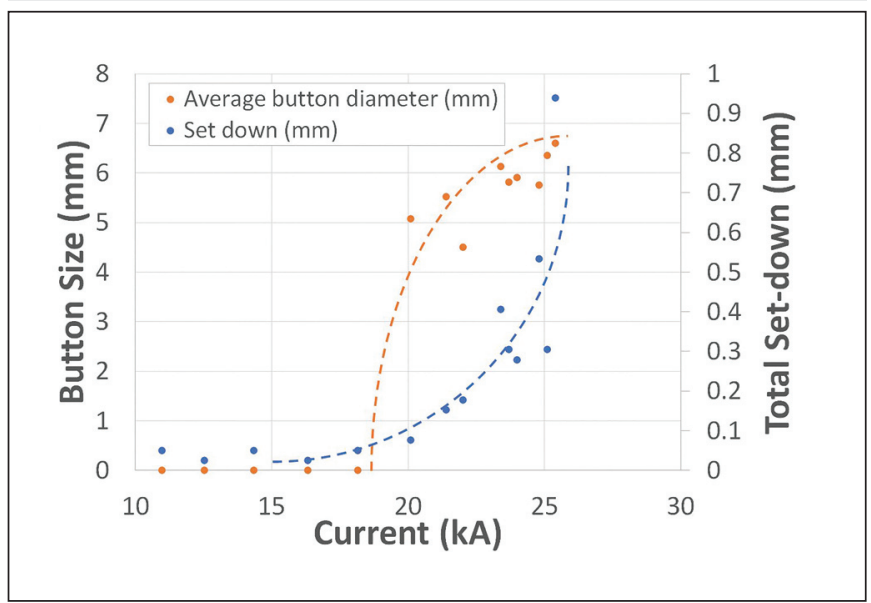

Fig. 9-Current range results when using the MFDC power supply. A current range of roughly $5 \mathrm{kA}$ is observed.

the secondary aging associated with heat soak away from the spot weld. Within the weld nugget, however, the hardness appears to drop considerably. Two factors may contribute to this: 1) solutionizing within the weld metal itself, and 2) the observed porosity that can facilitate excessive indentation.

The comparable current range data collected when using the $C D$ power supply was done under slightly different conditions. Here, weld force was increased to $4.4 \mathrm{kN}$. This was done to prevent expulsion between the aluminum sheet and the copper electrodes. The resulting current waveform is shown in Fig. 12. This current waveform was taken from a weld again made just below expulsion. The results include a very fast rise time $(\sim 2.5 \mathrm{~ms})$, a high peak current $(70 \mathrm{kA}$ shown), and a narrow overall pulse width $(\sim 10 \mathrm{~ms})$. The resulting current range data is provided in Table 3 . Here, currents were increased through the charge voltage on the capacitor. These voltages ranged from 1100 up to $2100 \mathrm{~V}$. This resulted in a current variation from 40 to $75 \mathrm{kA}$. Of note, all welds evaluated as part of current range testing were with the upper electrode positive. This was not by plan, but rather because current range testing requires two welds on a peel coupon. Therefore, the second weld (that subject to testing) was always made at the same polarity. Response 

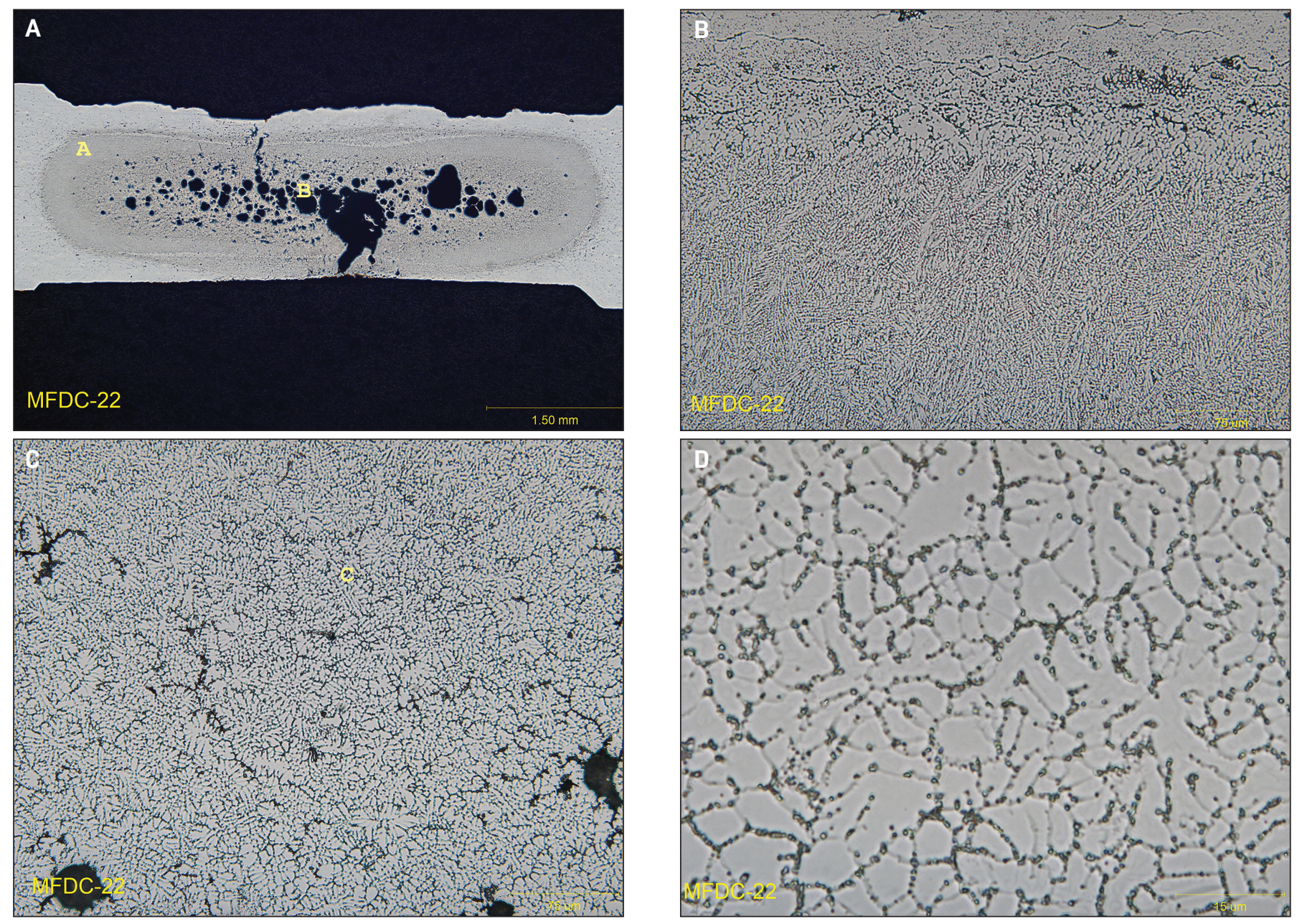

Fig. 10 - Microstructural details of a weld made using MFDC just below the expulsion limit: A - Macroview of the weld indicating regions " $A$ " and " $B$ " for more detailed assessment; B - region "A," the HAZ, showing evidence of liquation cracking along grain boundaries; $C$ - region " $B$ " showing large as-solidified grains and interdendritic solidification cracking; $D$ - higher magnification of region " $C$ " detailing the dendritic solidification structure with significant partitioning.

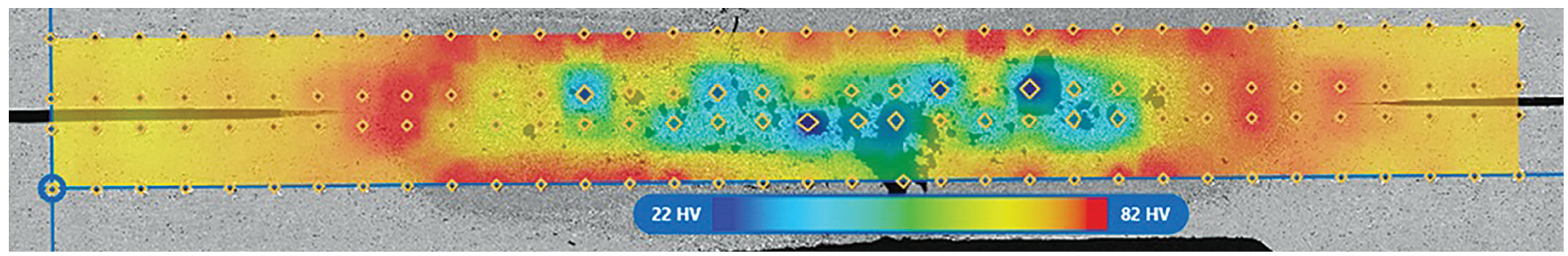

Fig. 11- Hardness map of a representative near-expulsion weld made using MFDC power.

variables for this current range test again included both the level of electrode indentation and the observed button size. In this case, indentations were relatively shallow. Total indentations ranged from 0.1 to $0.2 \mathrm{~mm}$ prior to expulsion. Even the expulsion weld showed only an indentation of about $0.3 \mathrm{~mm}$. Button sizes through this current range varied from 0 to a little over $5 \mathrm{~mm}$. Assuming a 4-mm minimum weld size, the current range was estimated at about $20 \mathrm{kA}$. The resulting current range is plotted in Fig. 13 , which shows that the weld size was relatively stable over a wide range of currents $(\sim 60-75 \mathrm{kA})$. In addition, the level of indentation was both low and only slightly influenced over a wide range of currents. The exception was when expul- sion occurred, nearly doubling the level of indentation (up to about $0.3 \mathrm{~mm}$ ).

Metallographic results for a representative $C D$ weld made near the top of the current range are provided in Fig. 14. This weld was made with a current of $70 \mathrm{kA}$. This represents a condition roughly $5 \mathrm{kA}$ below the expulsion limit. The macrosection of the weld is provided in Fig. 14A. which shows the joint penetration was relatively shallow $(\sim 50 \%)$, and there was only fine porosity along the bond line. Of note, the indentation on this weld was very limited. This is consistent with the measurements taken during current range testing. The weld was again augmented with symbols designating areas for additional microscopy. These included 


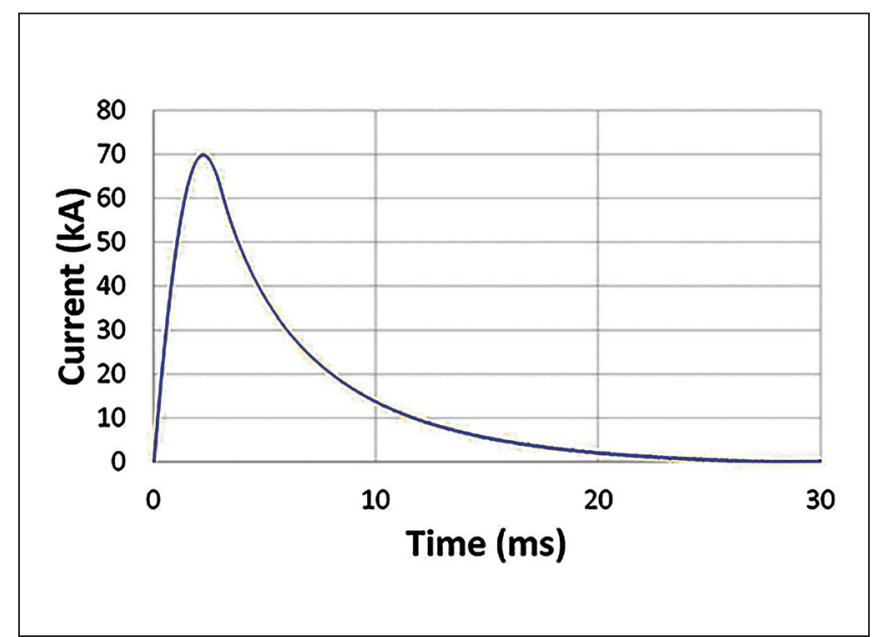

Fig. 12 - Current waveform for the welds made with the $C D$ power supply. Waveform was taken just below expulsion.

the HAZ (labeled with the yellow "A") and bond line region of the fusion zone (shown with the yellow letter "B").

Detail of the HAZ (Region "A") is provided in Fig. 14B. It shows that the grain structure was very fine, and there was little or no indication of liquation. Similar detail of the fusion zone centerline (Region "B") is shown in Fig. 14C. This micrograph suggests a structure of equiaxed solidified grains, though with limited indication of liquation cracking along the boundaries. A region " $\mathrm{C}$ " is indicated on this micrograph, showing an area for inspection at higher magnification. This is provided in Fig. 14D. This figure provides some detail of the solidification structure within these

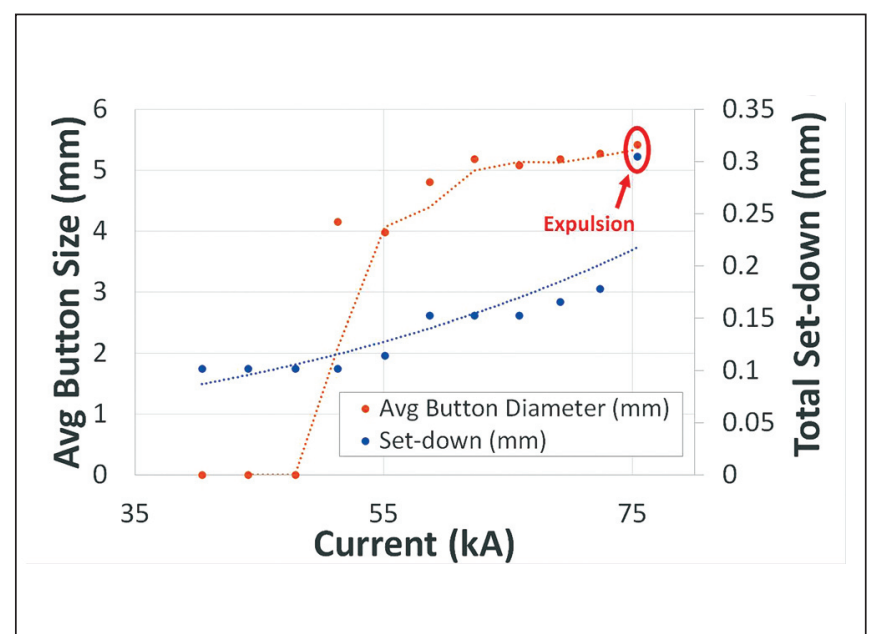

Fig. 13 - Current range results when using the $C D$ power supply. A current range of roughly $20 \mathrm{kA}$ is observed.

equiaxed grains. The scale is quite similar to that seen in the MFDC welds, though the level of segregation appears more diffuse.

This weld was also subjected to hardness mapping. The results from this map are provided in Fig. 15. Of first note is that the hardened areas in the HAZ are reduced both spatially and in magnitude compared to the MFDC weld. Furthermore, the decrease in hardness at the weld center is significantly reduced. This latter effect may be associated with the reduced level of porosity in the weld. Lower porosity levels provide a more rigid substrate for the hardness indenter, and thus the improved hardness levels seen here.

Table 3 - Data from Current Range Testing the 1-mm-thick Al 5182 When Using CD Equipment*

\begin{tabular}{|c|c|c|c|c|c|c|c|}
\hline Trial \# & $\begin{array}{l}\text { Windings } \\
\text { Ratio }\end{array}$ & $\begin{array}{c}\text { Weld } \\
\text { Force }(\mathrm{kN})\end{array}$ & $\begin{array}{c}\text { Charge } \\
\text { Voltage (V) }\end{array}$ & $\begin{array}{c}\text { Peak } \\
\text { Current (kA) }\end{array}$ & Polarity & $\begin{array}{l}\text { Set Down } \\
\text { (mm) }\end{array}$ & $\begin{array}{c}\text { Avg. Button } \\
\text { Diameter (mm) }\end{array}$ \\
\hline 43 & 75:1 & 4.4 & 1100 & 40.4 & + & 0.1 & 0 \\
\hline 44 & 75:1 & 4.4 & 1200 & 44.1 & + & 0.1 & 0 \\
\hline 45 & $75: 1$ & 4.4 & 1300 & 47.9 & + & 0.1 & 0 \\
\hline 47 & 75:1 & 4.4 & 1500 & 55.1 & + & 0.11 & 4 \\
\hline 48 & 75:1 & 4.4 & 1600 & 58.7 & + & 0.15 & 4.8 \\
\hline 51 & $75: 1$ & 4.4 & 1900 & 69.2 & + & 0.17 & 5.2 \\
\hline 52 & $75: 1$ & 4.4 & 2000 & 72.4 & + & 0.18 & 5.3 \\
\hline 53 & 75:1 & 4.4 & 2100 & 75.4 & + & 0.3 & 5.4 \\
\hline
\end{tabular}




\begin{tabular}{|c|c|c|c|c|c|c|c|}
\hline \multicolumn{8}{|c|}{ MFDC Welding Results } \\
\hline Sample \# & Strength (kN) & $\begin{array}{l}\text { Weld Diameter } \\
\text { (mm) }\end{array}$ & Button? & Sample \# & Strength (kN) & $\begin{array}{l}\text { Weld Diameter } \\
\qquad(\mathrm{mm})\end{array}$ & Button? \\
\hline 36 & 2.54 & 6.1 & $Y$ & 69 & 0.99 & 4.8 & $\mathrm{Y}$ \\
\hline 37 & 2.52 & 5.4 & $\mathrm{~N}$ & 70 & 1.05 & 4.6 & $\mathrm{Y}$ \\
\hline 38 & 2.39 & 6 & $\mathrm{Y}$ & 71 & 0.97 & 5 & $Y$ \\
\hline 39 & 2.36 & 5.5 & $\mathrm{~N}$ & 72 & 1.36 & 5.2 & $Y$ \\
\hline 43 & 2.47 & 6.2 & $\mathrm{Y}$ & 77 & 0.97 & 5 & $\mathrm{Y}$ \\
\hline 44 & 2.13 & 5.5 & $\mathrm{Y}$ & 78 & 1.47 & 5.3 & $\mathrm{Y}$ \\
\hline 45 & 2.44 & 6.3 & $\mathrm{Y}$ & 79 & 1.19 & 5.9 & $\mathrm{Y}$ \\
\hline 46 & 2.34 & 5.3 & $\mathrm{Y}$ & 80 & 1.95 & 5.2 & $\mathrm{Y}$ \\
\hline 47 & 2.27 & 5.9 & $\mathrm{Y}$ & 81 & 1.37 & 5 & $\mathrm{Y}$ \\
\hline 48 & 2.5 & 5.7 & $\mathrm{Y}$ & 82 & 1.1 & 4.5 & $\mathrm{Y}$ \\
\hline 49 & 2 & 5.4 & $\mathrm{Y}$ & 83 & 1.21 & 4.5 & $\mathrm{Y}$ \\
\hline 50 & 2.44 & 6.3 & $\mathrm{Y}$ & 84 & 1.12 & 4.4 & $\mathrm{Y}$ \\
\hline 51 & 2.66 & 5.9 & $\mathrm{Y}$ & 85 & 1.25 & 4.8 & $Y$ \\
\hline 58 & 2.58 & 5 & $Y$ & 92 & 1.13 & 4.8 & $\mathrm{Y}$ \\
\hline 59 & 2.25 & 5.3 & $Y$ & 93 & 1.21 & 4.7 & $Y$ \\
\hline 60 & 2.27 & 5.5 & $Y$ & 94 & 1.48 & 5.1 & $Y$ \\
\hline 61 & 2.12 & 6 & $Y$ & 95 & 1.96 & 5.3 & $Y$ \\
\hline 62 & 2.31 & 5.6 & $Y$ & 96 & 0.92 & 4.6 & $Y$ \\
\hline 63 & 2.27 & 5.6 & $\mathrm{Y}$ & 97 & 1.25 & 5.7 & $\mathrm{Y}$ \\
\hline 64 & 2.45 & 5.3 & $Y$ & 98 & 1.19 & 5.6 & $Y$ \\
\hline 65 & 1.93 & 6.5 & $Y$ & 99 & 1.13 & 4.8 & $\mathrm{Y}$ \\
\hline 66 & 2.27 & 6.4 & $\mathrm{Y}$ & 100 & 1.16 & 4.9 & $\mathrm{Y}$ \\
\hline 67 & 2.35 & 5.9 & $Y$ & 101 & 1.01 & 5 & $Y$ \\
\hline
\end{tabular}

Best practices taken from the current range results presented above for both MFDC and CD welding were then used to create mechanical properties specimens. For these specimens, MFDC welds were made at conditions of 5-mm electrode diameter, 4-kA/40-ms prepulse, 20-kA/80-ms main pulse, and 2.2-kN contact force. $\mathrm{CD}$ welds were made using a 5-mm electrode, 2.5-ms rise time, 70-kA peak current, and $4.4-\mathrm{kN}$ contact force. For each power supply variant/test con- figuration, 33 replicate samples were made. Replicate mechanical test results for welds made using MFDC power are provided in Table 4 . Similar results for the $C D$ welds are provided in Table 5. Within each table (replicated for each type of mechanical test), the sample number, measured failure strength, average weld size (average of the major and minor diameters), and mode of failure are recorded. Where button pull-out was not observed, the apparent weld diameter at the 

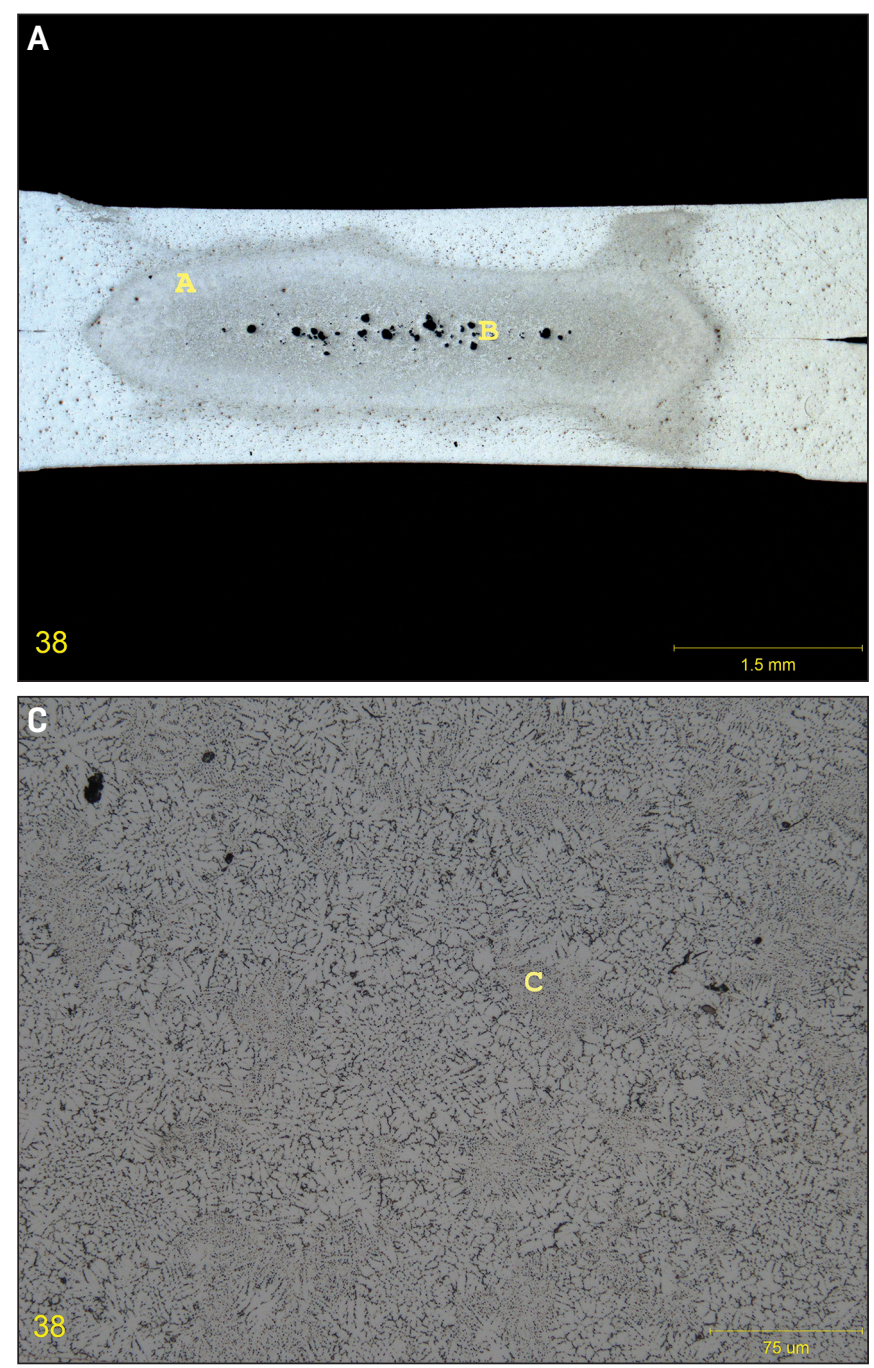
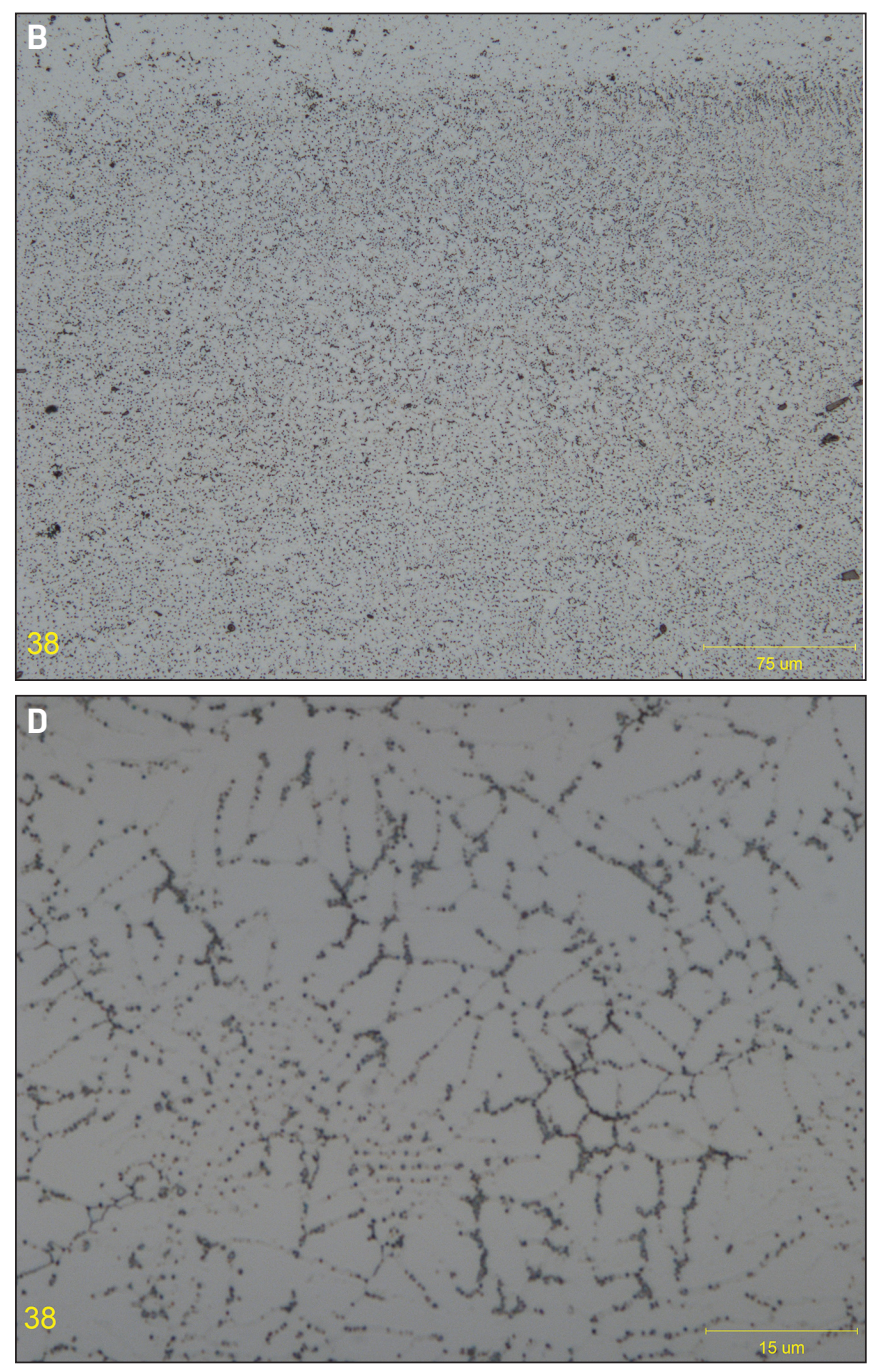

Fig. 14 - Microstructural details of a weld made using CD current just below the expulsion limit: $A-$ Macroview of the weld indicating regions " $A$ " and "B" for more detailed assessment; $B$ - region "A," the HAZ, showing a fine recrystallized structure; $C$ region " $B$ " showing large as-solidified grains and some inter-dendritic solidification cracking; $D$ - higher magnification of region " $\mathrm{C}$ " detailing the dendritic solidification structure.

faying surface was measured. Nearly all welds made using MFDC power failed by button pull-out. All tensile shear tested $C D$ welds failed by nugget shear (no button). In this case, failure was by shearing of the aluminum across the area of bonding. Cross-tension specimens, however, all failed by button pull-out.

Joint strength results for both power supply types are presented graphically in Fig. 16. The plot presents, for each combination of power supply type and mechanical test configuration, joint strength as a function of measured button size. As expected, shear strengths were roughly double those for cross-tension testing. This observation is common for spot welds on steels (Ref. 3). Cross-tension strengths for both the MFDC and CD welds averaged about $1.2 \mathrm{kN}$ with scatter over a range of nominally $\pm 300 \mathrm{~N}$. Also, the spread in cross-tension data was nearly identical for the two power supply types.

There was, however, clear separation in the tensile shear data for the two power supply types. The MFDC and CD data averaged shear strengths of roughly 2.4 and $2.9 \mathrm{kN}$, re- spectively. The scatter for these two datasets was similar, however, nominally around $\pm 300 \mathrm{~N}$. The measured button sizes for each dataset averaged 5.0-5.5 mm. The scatter for each data set averaged $\pm 0.7- \pm 1 \mathrm{~mm}$.

The final set of trials included evaluating applicability of $C D$ welding in the presence of an adhesive. The work was carried out as two current range tests: one with a prepulse and one without a prepulse. Each current range test followed the approach described previously. For welding through adhesives, prepulses are often used to allow displacement of the organics before the main current is initiated. Data from the current range curves with and without the prepulse are presented in Table 6. Welds 1-12 were done with the prepulse. The prepulse energy was roughly $5 \%$ of the main pulse. The data for the trials without the prepulse are provided as welds 13-24.

The resulting current range curves are provided graphically in Fig. 17. Again, a 4-mm minimum button size was superimposed on this plot. For both conditions, current ranges on the order of $30 \mathrm{kA}$ were observed. Of interest, the 


\section{WELDING RESEARCH}

Table 5 - Tensile Shear and Cross-Tension Results of 33 Replicate CD-Welded Samples (Each) Using Identical Programmed Welding Conditions

CD Welding Results

Tensile Shear Test Results

Cross-Tension Test Results

$\begin{array}{ccccccc}\text { Sample \# } & \text { Strength }(\mathrm{kN}) & \begin{array}{c}\text { Weld Diameter } \\ (\mathrm{mm})\end{array} & \text { Button? } & \text { Sample \# } & \text { Strength }(\mathrm{kN}) & \begin{array}{c}\text { Weld Diameter } \\ (\mathrm{mm})\end{array}\end{array}$

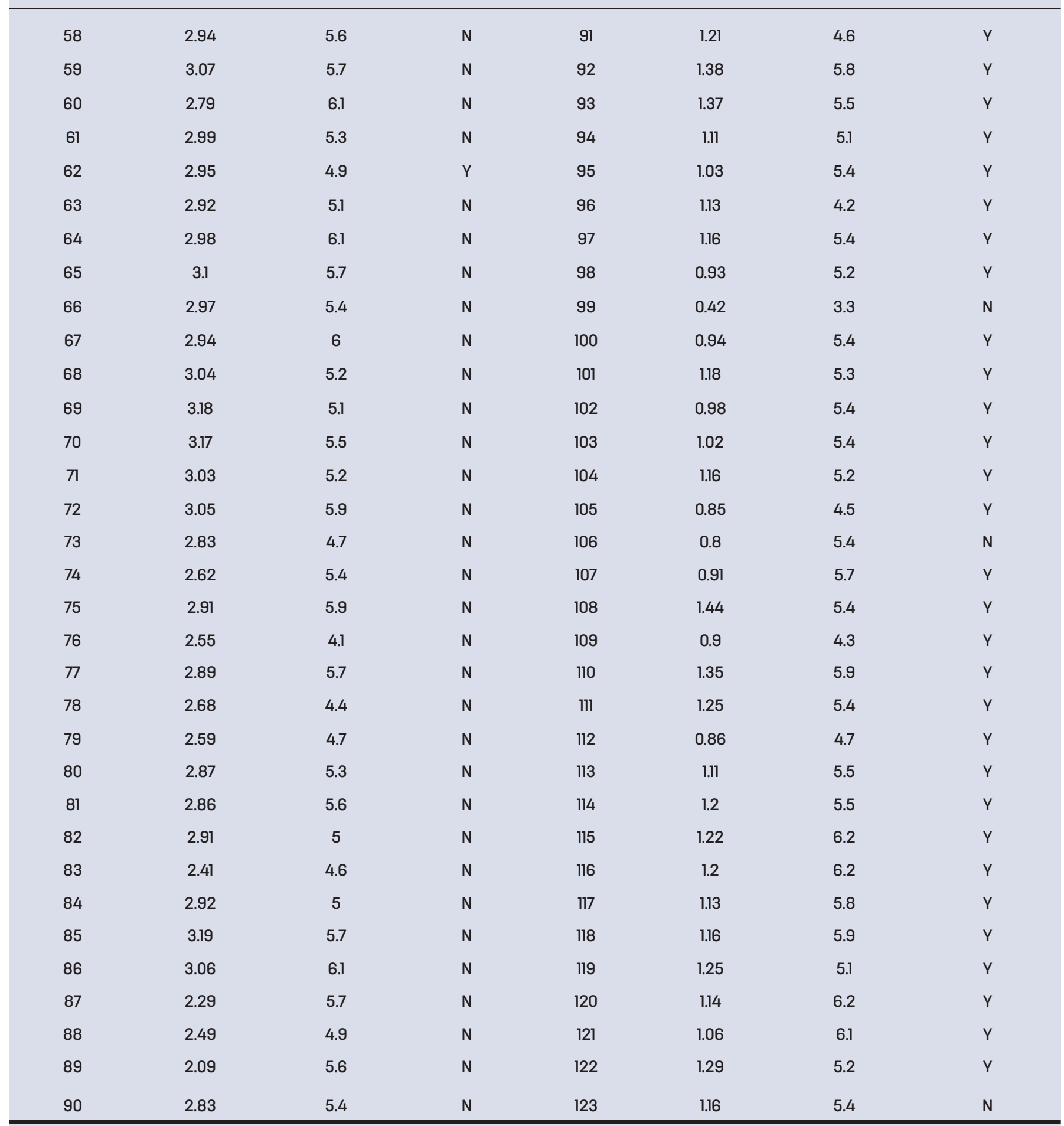




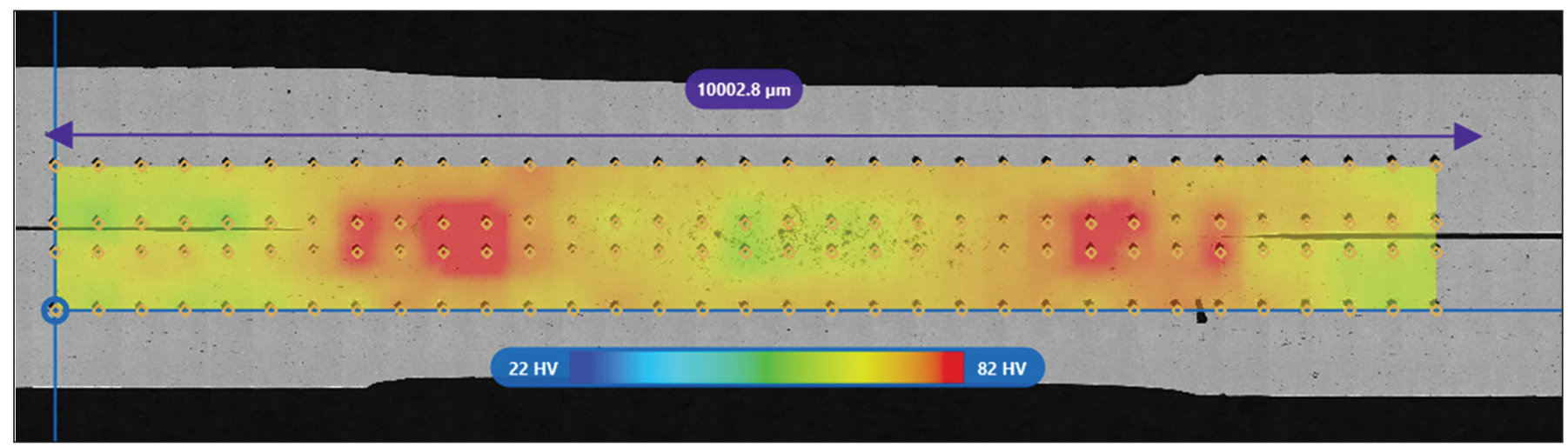

Fig. 15 - Hardness map of a representative near-expulsion weld made using $C D$ power.

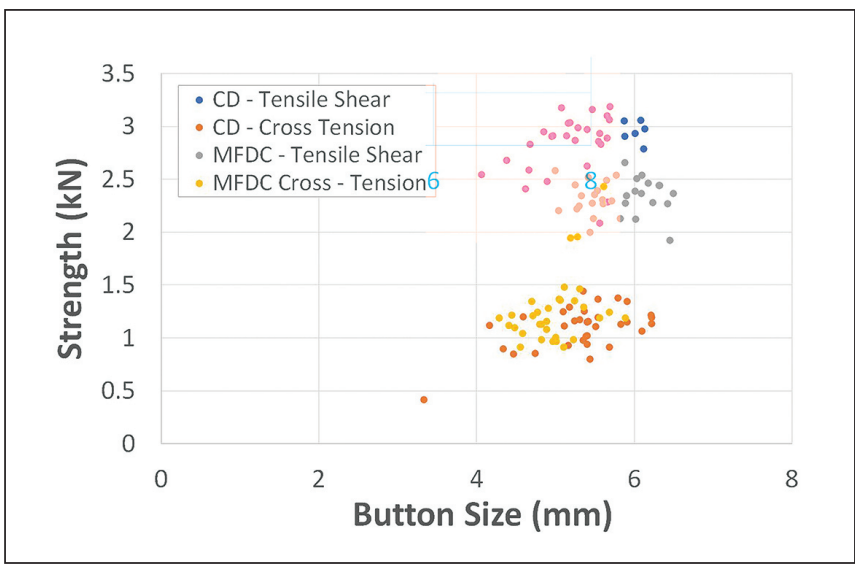

Fig. 16 - Strength as a function of button size for the replicate sets of tensile shear and cross-tension data taken for the two power supply types.

current range curves for the two conditions lay completely on top of each other. There appeared to be little difference in process response whether or not the prepulse was applied. Some sample peel tested welds taken from the current range curves with and without a prepulse are provided in Figs. 18 and 19. Both samples demonstrated how the adhesive is redistributed over the area for joining. The resulting spot welds were well located in the adhesive-affected area. The resulting buttons show an annulus of adhesive-free material nominally $1-\mathrm{mm}$ wide both with and without the prepulse. The resulting buttons were uniform with no indication of weld metal failure.

\section{Discussion}

The results presented above suggest that polarityswitching CD-based resistance spot welding offers considerable advantages over the conventional MFDC variant with respect to the current range behavior and resulting peak mechanical strengths. Additionally the technology has shown to be compatible for joining through conventional adhesives.

The polarity-switching $C D$ system offers two unique characteristics that impact the performance attributes described in this study. The first is the relative time domain of the current pulse and the second is polarity management. The former is of primary interest when considering basic resistance spot weldability. A direct comparison of the $C D$ and

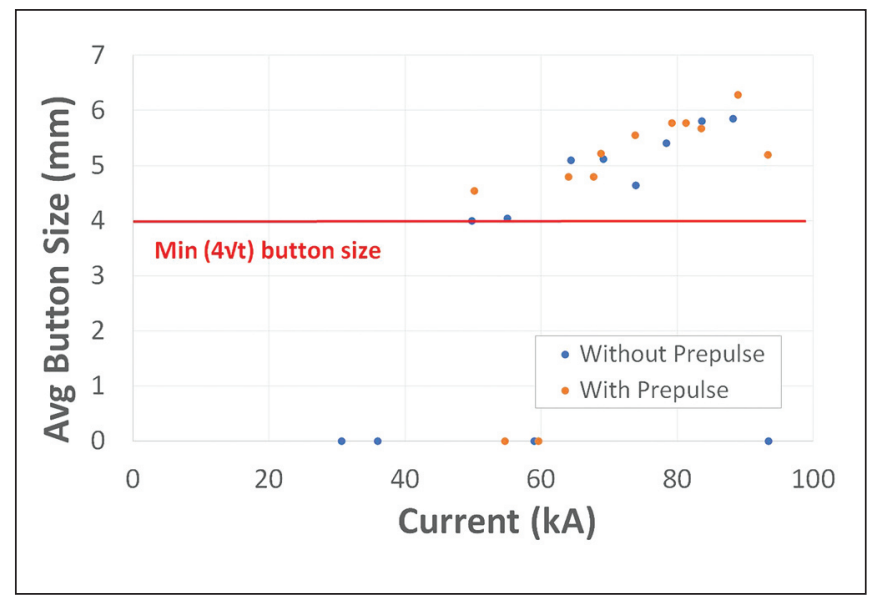

Fig. 17 - Comparative current range curves for $C D$ welding through an adhesive with and without the use of preheat.

MFDC current waveforms for welds made in this study is provided in Fig. 20. Here, the waveforms are plotted on the same current and time scales. It is clear for the application investigated here that $C D$ welding provides roughly three times the welding current and an order-of-magnitude shorter time. Higher currents, of course, react preferentially with the contact resistances when welding aluminum. It is well documented that contact resistances during spot welding of aluminum decay rapidly. Previous work (Refs. 4, 6) has shown that these contact resistances drop from hundreds of micro-ohms to nearly single-digit values in one or two milliseconds. As a result, shorter current pulses will tend to react to, particularly, with the faying surface resistances, promoting formation of a localized nugget. Shorter pulses also limit the degree of heat soak through the workpieces or into the electrodes. This effect tends to create reduced penetration joints, but it also minimizes any excessive heating of the electrodes themselves.

An example of the latter is provided in Table 7, which shows heat soak distances for the two current width pulses seen in this work combined with available thermal data for aluminum and copper. The equation for heat soak is taken from a Zener approximation thermal analysis of resistance spot welding described elsewhere (Ref. 22). The results suggest heat penetration distances for the $\mathrm{CD}$ pulses used are on the order of a millimeter, compared to several millimeters for the MFDC weld. Given the sheets welded are only 1 


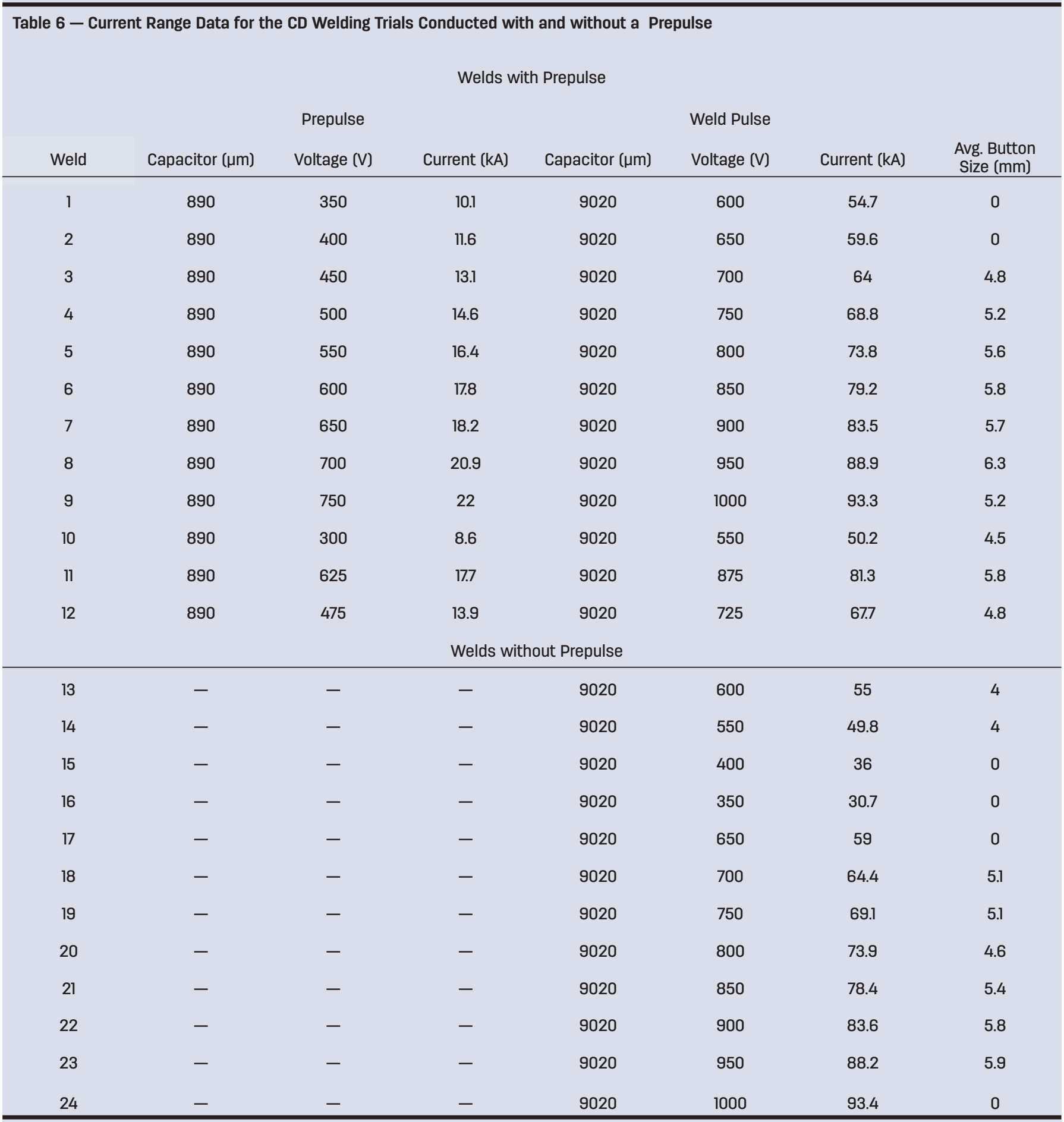

mm thick, these differences are significant.

Basic weldability, as defined by the current range curves, appears to benefit from this heat concentration at the contact surfaces. Comparing such curves when the current levels themselves differ by a factor of three can be difficult. To provide better insights, the two current ranges normalized to the expulsion current are provided in Fig. 21.

The upper plot here presents the button size data, while the lower presents the degree of indentation. Results show that even when the data is normalized in this way, current ranges using $C D$ power are still roughly $50 \%$ greater than those for MFDC. These wider current ranges and reduced indentation are directly the result of the shorter overall heating pulses. As the micrographs shown in Figs. 12A and 14A indicate, the shorter, more intense $C D$ weld pulses result in nuggets concentrated at the faying surface with reduced penetration. Such welds are less prone to expulsion, thus enabling both the wider current ranges and reduced indentation. 


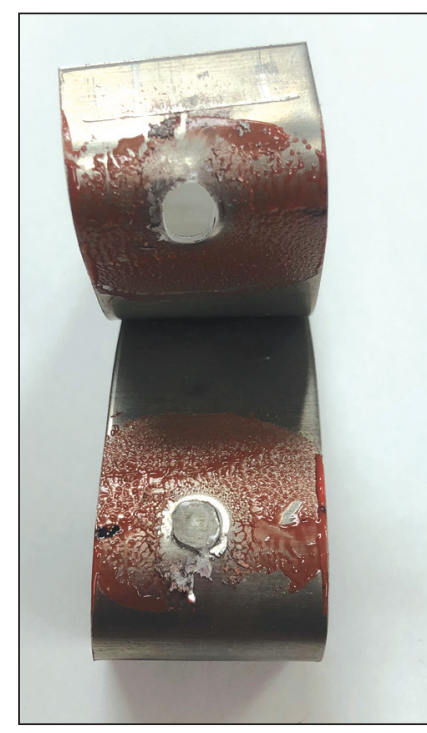

Fig. 18 - Peel test coupon taken near the expulsion limit from the current range with adhesive and prepulse.

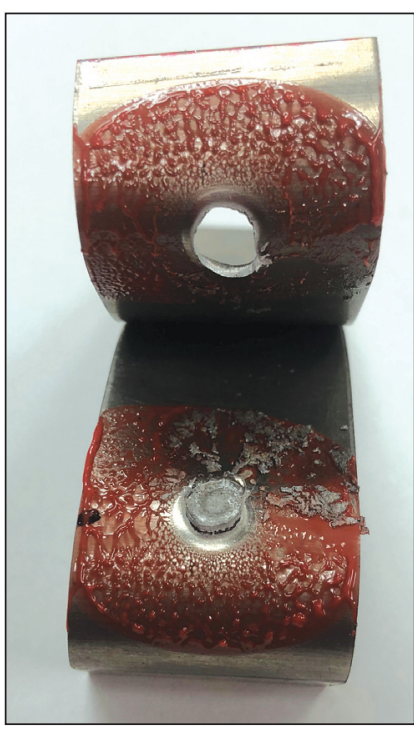

Fig. 19-Peel test coupon taken near the expulsion limit from the current range with adhesive and without prepulse.
Replicate mechanical testing also showed some influence of this heat time. Interestingly, the spread in the data and resulting button sizes for $C D$ and MFDC welding appeared nearly identical for both 2tensile shear and cross-tension tests. However, CD welds showed significantly higher tensile shear strengths and a tendency toward button shear compared to those made with MFDC power. Here, the reduced apparent hardening around the nugget associated with the reduced heat penetration of the $C D$ weld appeared to accentuate shear types of failure. A similar effect was not noted for the cross-tension welds, as the geometric affects associated with peeling appeared to mitigate any microstructural aspect.

\section{Conclusions}

In this work, the applicability of polarity-switching CDbased resistance spot welding to aluminum sheet was investigated. Such power supplies are of interest for spot welding aluminum sheet for the implicit narrow pulse widths and inherent polarity switching. This addressed three aspects of resistance welding, including assessments of current ranges (for process robustness), determination of baseline mechanical properties (and their reproducibility), electrode life, and compatibility with adhesives. Current range results showed the process to be quite robust, resulting in very little electrode indentation into the sheet surfaces. Mechanical property results equaled or exceeded those for MFDC welding, with similar levels of variation in the data. Finally, polarityswitched CD welding was found to be compatible with a representative adhesive. The results presented here also provide background data for the electrode life results to be presented in a follow-on paper. Individual conclusions from this work are described below:

1) Current range results when using polarity-switched
CD power exceeded those for MFDC welding: Actual current ranges for polarity-switched $C D$ welding were on the order of four times as wide than seen for MFDC welding. When normalized for the measured expulsion current, the polarity-switched CD current range was still 50\% wider than for MFDC welding.

2) Polarity-switched $C D$ welding resulted in weld nuggets with shallower penetration, reduced internal porosity, and significantly less indentation compared to MFDC welding: Rapid thermal cycles preferentially reacted with the faying surface contact resistance and restricted thermal penetration heat flow into the component sheets. This resulted in reduced nugget penetration and less softening of the aluminum adjacent to the electrodes.

3) Hardness variations across the aluminum workpiece were reduced when using polarity-switching CD welding: The rapid thermal cycle associated with polarity-switching $C D$ welding appears to have minimized the secondary hardening observed in the HAZ around the nugget. In addition, significantly less softening of the weld nugget itself was noted, though this may be related to the reduced porosity seen in the CD welds.

4) Variations in both tensile shear and cross-tension strengths for both polarity switching CD and MFDC welding were similar: All test datasets showed strengths that were consistent within roughly $\pm 300 \mathrm{~N}$

5) Tensile shear strengths for the polarity-switching CD welds were about $500 \mathrm{~N}$ stronger than those made with MFDC power: This strength difference was noted even though the CD welds failed by weld nugget shear and the MFDC welds by button pull-out. Though not directly observed on the hardness maps, this must be related to some softening in the HAZ for the longer thermal cycling MFDC welding process.

6) Welding of aluminum sheet with adhesives was readily accomplished using CD-based resistance spot welding: Resistance spot welding of aluminum sheet with an adhesive present at the faying surface was readily accomplished. Stable welding performance (and current ranges) were seen with and without a prepulse in the welding schedule. This may be due to the preferential heating that occurs at the faying surface with the shorter pulse, or an adhesive variant that has low viscosity at elevated temperature.

7) Candidate practices for the electrode life studies described in Part 2 of this series were developed: Best practices here are used as the basis for the electrode life valuations to be described in a follow-on paper (Ref. 17).

\section{References}

1. Gould, J. E. 2008. Joining aluminum sheet in the automotive industry - A 30-year history. Welding Journal 91(1): 23-s to 43-s.

2. Dickinson, D. W. 1981. Welding in the Automotive Industry. Committee of sheet steel producers, Report 81-5.

3. Dilay, W., Rogola, E. A., and Zulinski, E. J. 1977. Resistance welding aluminum for automotive production. SAE Technical Paper 770305. SAE International, Warrendale, Pa. DOI: 10.4271/770305

4. Patrick, E. P., Auhl, J. R., and Sun, T. S. 1984. Understanding the process mechanisms is key to reliable resistance spot welding aluminum auto body components. SAE Technical Paper 84029. SAE International, Warrendale, $\mathrm{Pa}$. 


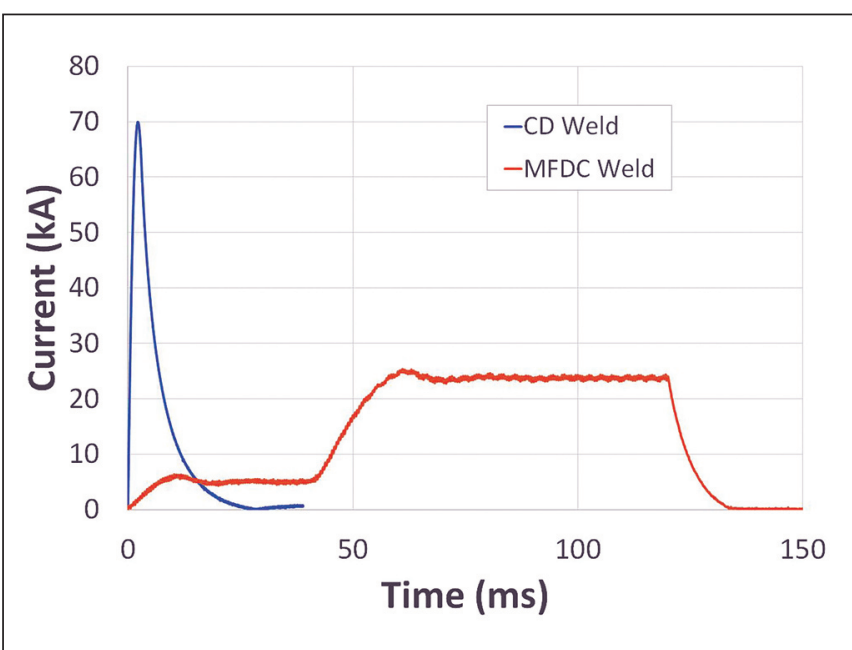

Fig. 20 - Direct comparison of the MFDC and CD current waveforms used in this study.

Table 7 - Estimated Thermal Penetration into the Aluminum Sheet and Copper Electrode

$\begin{array}{cc}\text { Heat Soak Equation: } & x=\sqrt{2 \alpha t} \\ \begin{array}{c}\text { Heat Time } \\ (\mathrm{ms})\end{array} & \text { Thermal Diffusion } \\ \text { Distance }(\mathrm{mm})\end{array}$

\begin{tabular}{ccc}
\hline & Al & $\mathrm{Cu}$ \\
10 & 1.2 & 1.5 \\
120 & 4.1 & 5.3 \\
\hline
\end{tabular}

5. Keay, B. B. 1992. Welding of aluminum for auto body assembly. Sheet Metal Welding Conference V, Paper D4. AWS Detroit Section, Detroit, Mich.

6. Auhl, J. R., and Patrick, E. P. 1994. A fresh look at resistance spot welding of $\mathrm{Al}$ automotive components. SAE Paper 94160. SAE International, Warrendale, $\mathrm{Pa}$.

7. Spinella, D. J., and Patrick, E. P. 2002. Advancements in aluminum resistance spot welding to improve performance and reduce energy. Sheet Metal Welding Conference X, Paper 3-6. AWS Detroit Section, Detroit, Mich.

8. Li, Z., Hao, C., Zhang, J., and Zhang, H. 2007. Effects of sheet surface conditions on electrode life in resistance welding aluminum. Welding Journal 86(4): 81-s to 89-s.

9. Lum, I., Fukumoto, S., Biro, E., Boomer, D. R., and Zhou, Y. 2004. Electrode pitting in resistance spot welding of aluminum alloy 5182. Metallurgical and Materials Transactions A 35(1): 217226. DOI: $10.1007 / \mathrm{s} 11661-004-0122-8$

10. Rooks, B. Advances in resistance welding for body-in-white. 2003. Assembly Automation 23(2): 159-162. DOI: 10.1108/ 01445150310471400

11. Kimchi, M., and Phillips, D. H. 2017. Resistance spot welding: Fundamentals and applications for the automotive industry. Synthesis Lectures on Mechanical Engineering 1(2): 1-115. DOI: 10.2200/S00792ED1V01Y201707MEC005

12. Fukumoto, S., et al. 2003. Effects of electrode degradation on electrode life in resistance spot welding of aluminum alloy 5182. Welding Journal 82(11): 307-s to 312-s.

13. Peng, J., Fukumoto, S., Brown, L., and Zhou, N. 2004. Image analysis of electrode degradation in resistance spot welding of aluminum. Science and Technology of Welding and Joining 9(4): 331-336. DOI: 10.1179/136217104225012256

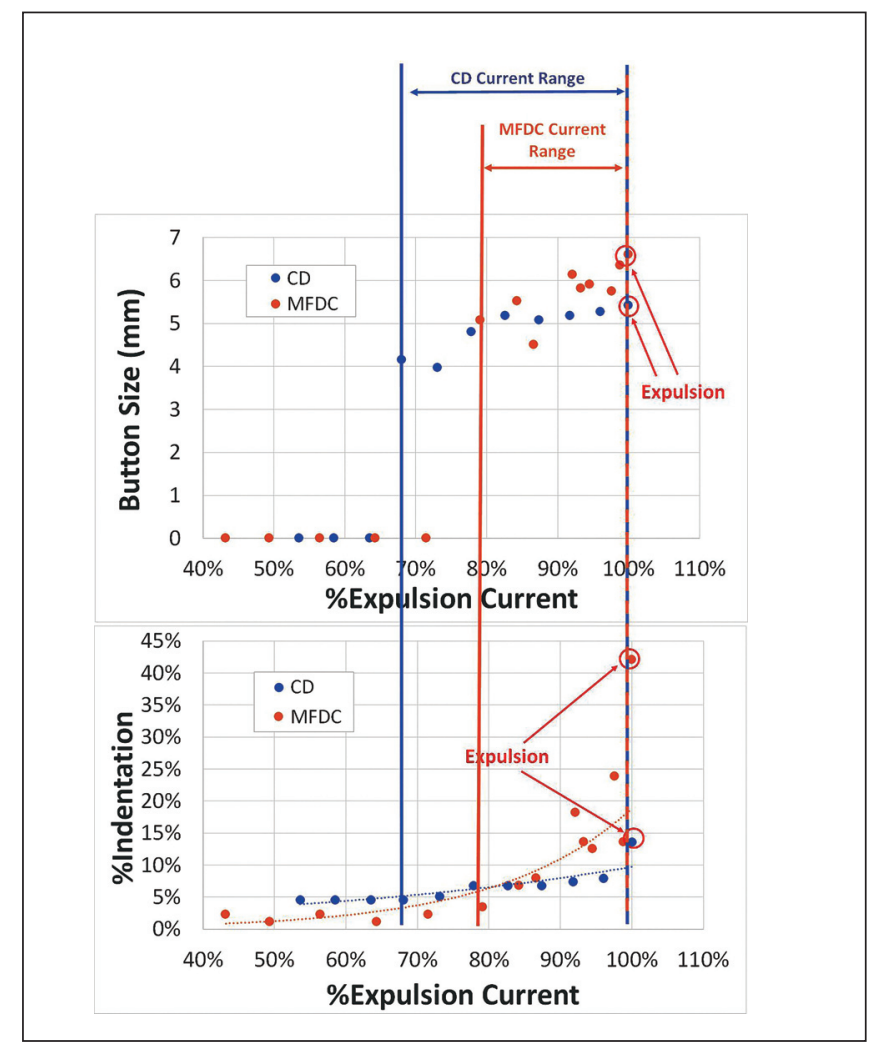

Fig. 21 - Current range results for the MFDC and $C D$ power supplies shown normalized to their respective expulsion currents. The upper plot presents the variation in weld button size, and the lower presents the degree of indentation.

14. Schondelmayer, C. A., and Crist, C. W. 2016. Benefits of reversing DC power supplies (RDC) on RSW applications. Sheet Metal Welding Conference XVII, Paper 3B-1. AWS Detroit Section, Detroit, Mich.

15. Gould, J. E., and Lewis, S. 2021. Capacitive discharge welding system. U.S. Patent 10,967,454 B1.

16. Gould, J. E., and Lewis, S. 2016. Development of an open architecture capacitive discharge welding system. Sheet Metal Welding Conference XVII, Paper 3B-5. AWS Detroit Section, Detroit, Mich.

17. Gould, J. E., Lindamood, L., Malpica, J., Lester, P., and Zhu, D. 2020. Capacitor discharge spot welding of aluminum, Part 2: Electrode life assessments. Submitted to Welding Journal.

18. ASM International 1990. Metals Handbook-Properties and Selection: Nonferrous Alloys and Special-Purpose Materials, Vol. 2, Ed. 10. ASM International, Materials Park, Ohio.

19. AWS C1.1M/C1.1:2000(R2006), Recommended Practices for Resistance Welding. American Welding Society, Miami, Fla.

20. AWS D8.9M:2012, Test Methods for Evaluating the Resistance Spot Welding Behavior of Automotive Sheet Steel Materials. American Welding Society, Miami, Fla.

21. ASTM E384-11, Standard Test Method for Knoop and Vickers Hardness of Materials. American Society for Testing and Materials, West Conshohocken, Pa.

22. Gould, J. E. 2018. Use of a zener approximation for heat transfer analyses of quasi one-dimensional welding problems. $\mathrm{Ma}$ terials Science Forum 941: 2313-2318. Trans Tech Publications. DEWEI ZHU are with Novelis Global Technology Center, Atlanta, Ga. 